\title{
[Mg-Al]-LDH and [Zn-Al]-LDH as Matrices for Removal of High Loadings of Phosphate
}

\author{
Marcela Piassi Bernardo $^{a, b} \mathbb{D}$, Caue Ribeiro ${ }^{a, b} *$ \\ ${ }^{a}$ Departamento de Química, Universidade Federal de São Carlos, Rodovia Washington Luís, \\ 13565-905, São Carlos, SP, Brasil \\ ${ }^{b}$ Laboratório Nacional de Nanotecnologia Aplicada ao Agronegócio (LNNA), Embrapa Instrumentação, \\ Rua XV de Novembro, 1452, 13560-970, São Carlos, SP, Brasil
}

Received: November 10, 2017; Revised: January 29, 2018; Accepted: February 09, 2018

\begin{abstract}
Eutrophication is an undesirable environmental process that occurs in water bodies affected by high concentrations of phosphate. Different economic sectors are responsible for discharge effluents with extremely high phosphate content. Therefore, is important to develop technologies capable of remove phosphate from these effluents, before that reach other and larger water bodies. This work proposes the use of layered double hydroxide $(\mathrm{LDH})$ as an adsorbent matrix for phosphate removal from aqueous solution. Different isomorphic structure of LDH ([Mg-Al]-LDH and [Zn-Al]-LDH) were employed to incorporate loadings of phosphate by ion exchange. The obtained materials were characterized by X-ray powder diffraction (XRD), scanning electron microscopy (SEM), fourier transform infrared spectroscopy (FTIR), and thermal analysis (TG/DTG). The crystalline structure of $[\mathrm{Mg}-\mathrm{Al}]-\mathrm{LDH}$ was preserved after phosphate adsorption, however the performance was low in comparison to [Zn-Al]-LDH, for which a high phosphate removal efficiency of $116.07 \mathrm{mg} \mathrm{P}^{-1}$ of $\mathrm{LDH}$ was achieved. The [Zn-Al]-LDH material showed good potential for use as matrix for the adsorption of phosphate in effluents.
\end{abstract}

Keywords: Eutrophication, phosphate removal, hydrotalcite, anion adsorption, ion exchange.

\section{Introduction}

Wastewaters from different economic sectors and from human activities are concerning due to the high phosphate content of these effluents. Swine wastes can achieve phosphate concentrations around $1000 \mathrm{mg} \cdot \mathrm{L}^{-1},{ }^{1}$ while the wastewater produced by the cochineal extract process to obtain the carminic acid colouring pigment (carmin red E120) has high concentrations of phosphates, about $3500 \mathrm{mg} . \mathrm{L}^{-1} .^{2}$ In a similar way, other activities generate wastewater products with high phosphate concentration, like agriculture, animal breeding and domestic activities. ${ }^{3-6}$

In most of the cases, the effluents are not treated and are simply thrown into rivers where they contribute to eutrophication, which occurs when the concentrations of nutrients in water bodies increase, resulting in intense reproduction of autotrophic organisms, especially algae and cyanobacteria. The increased respiration of autotrophs then leads to environments that are hypoxic or anoxic, threatening the aerobic fauna and flora. ${ }^{7,8}$ Thus, the treatment of the wastewaters prior the discharge is of crucial importance.

It is extremely important the development of technologies capable to remove phosphate from effluents with medium to high phosphate concentration content. Biological methods of recovery have been employed since the 1950s, although such techniques typically remove only $10-30 \%$ of the phosphate present. Another effective and economic technological option for phosphate removal is to use adsorbents. ${ }^{9}$

Layered double hydroxides (LDHs) are excellent materials for removal of phosphate from contaminated area due to their unique structure, high specific surface area, and low synthesis costs. ${ }^{10}$ LDHs are a class of two-dimensional nanostructured anionic clays whose crystalline structure can be described as positive layers of brucite $\left(\mathrm{Mg}(\mathrm{OH})_{2}\right)$, in which trivalent cations replace isomorphically divalent cations at the octahedral sites. The net positive charge of the LDH lamellae is then counterbalanced by $\mathrm{A}^{\mathrm{n}-}$ species in the interlamellar domains. Water molecules can also occupy the free space in the interlamellar region. ${ }^{11-14}$

LDHs can be represented by the following general formula: $\left[\mathrm{M}^{2+}{ }_{1-\mathrm{x}} \mathrm{M}^{3+}{ }_{\mathrm{x}}(\mathrm{OH})_{2}\right]^{\mathrm{x}+}\left(\mathrm{A}^{\mathrm{n}-}\right)_{\mathrm{x} / \mathrm{n}} \cdot m \mathrm{H}_{2} \mathrm{O}$, where $\mathrm{M}^{2+}$ and $\mathrm{M}^{3+}$ are divalent and trivalent cations, respectively; the value of $x$ is equal to the molar ratio $\mathrm{M}^{3+} /\left(\mathrm{M}^{2+}+\mathrm{M}^{3+}\right)$; $\mathrm{A}$ is the interlamellar anion with valence of $\mathrm{n}^{-}$. Variation of $\mathrm{M}^{2+}, \mathrm{M}^{3+}, x$, and $\mathrm{A}^{\mathrm{n}-}$ enables the formation of a broad class of isostructural materials with different physical-chemical properties. ${ }^{13,14}$ LDHs have high ion exchange capacity, since the interlamellar regions are flexible in terms of the content of anionic species. This important characteristic provides LDHs with excellent potential for use in the removal of contaminants by ion exchange processes. ${ }^{14}$ 
The adsorption at LDHs can occur in, at least, two ways involving superficial adsorption or ion exchange in the interlamellar space. Superficial adsorption involves the adhesion of ionic compounds on the LDH surface, with the formation of molecular or atomic films. The ion exchange process is mainly influenced by the anionic charge balance in the interlamellar space and the charge density of the lamellae. ${ }^{14}$ It has been observed that divalent anions $\left(\mathrm{A}^{2-}\right)$ of LDHs can be easily replaced by monovalent anions. ${ }^{15}$

LDHs have been employed for the removal of a variety of anions including fluorite, ${ }^{16}$ selenium, ${ }^{17}$ arsenate, ${ }^{18}$ perchlorate, ${ }^{19}$ chromium, ${ }^{20}$ and phosphate. ${ }^{21,22}$ However, the mechanisms of adsorption of phosphate by LDHs have received little attention and remain poorly understood. ${ }^{23}$ The aim of this work was to compare the effects of magnesium and zinc on LDH adsorption properties of high phosphate concentrations, since both have the same valence but very different ionic sizes. The [Mg-Al]-LDH is the best known and explored type of layered double hydroxide and it was used as standard to phosphate adsorption comparison. On the other hand, [Zn-Al]-LDH has been extensively used, as selenium and fluoride adsorbent. ${ }^{17,18}$ These materials may have different adsorption properties, due to the intrinsically associated differences in the structure, since different ionic radius will influence on the size of each adsorption site. In this sense, the [Mg-Al]-LDH and [Zn-Al]-LDH were chosen as inorganic matrices for phosphate adsorption study.

\section{Materials and Methods}

\subsection{Materials}

Zinc chloride $\left(\mathrm{ZnCl}_{2}\right)$, aluminum chloride hexahydrate $\left(\mathrm{AlCl}_{3} \cdot 6 \mathrm{H}_{2} \mathrm{O}\right)$, sodium hydroxide $(\mathrm{NaOH})$, sodium carbonate $\left(\mathrm{Na}_{2} \mathrm{CO}_{3}\right)$, and potassium phosphate monobasic $\left(\mathrm{KH}_{2} \mathrm{PO}_{4}\right)$ were purchased from Synth (Brazil). Commercial [Mg-Al]-LDH hydrotalcite (Pural) was purchased from Sasol (Germany). All reagents were used as received. Decarbonated deionized water $(\rho=18.2 \mathrm{M} \Omega \mathrm{cm})$ obtained from a Milli-Q system (Barnstead Nanopure Diamond, Thermo Fisher Scientific Inc., Dubuque, IA, USA) was used in all the experimental procedures.

\subsection{Synthesis of [Zn-Al]-LDH}

[Zn-Al]-LDH with $\mathrm{M}^{3+} /\left(\mathrm{M}^{2+}+\mathrm{M}^{3+}\right)$ molar ratio $(x)$ of 0.25 was synthesized by the co-precipitation method, with pH control. ${ }^{13}$ The synthesis was carried out in an all-glass reactor (capacity of $300 \mathrm{~mL}$ ) attached to a water circulating system to accurately control the temperature at $25.0^{\circ} \mathrm{C}( \pm 0.5$ $\left.{ }^{\circ} \mathrm{C}\right)$. In a typical reaction, a mixed chloride solution $(0.5 \mathrm{~mol}$ $\mathrm{L}^{-1}$ ) containing $\mathrm{Zn}^{2+}$ and $\mathrm{Al}^{3+}$ cations was gradually injected at a rate of $0.5 \mathrm{~mL} \mathrm{~min}^{-1}$ into the reactor containing sodium hydroxide solution $\left(1.0 \mathrm{~mol} \mathrm{~L}^{-1}\right)$, under vigorous stirring. At the same time, a solution of $\mathrm{Na}_{2} \mathrm{CO}_{3}\left(2 \mathrm{mmol} \mathrm{L}^{-1}\right)$ was injected at a rate of $0.025 \mathrm{~mL} \mathrm{~min}^{-1}$ for $\mathrm{pH}$ control. Once injection of the solutions was complete, agitation was continued for a further hour, to age the precipitate. Subsequently, the mixture was centrifuged at 11,200 $g$ for $10 \mathrm{~min}$ to remove the excess $\mathrm{NaCl}$. The precipitate was then purified using three washingcentrifugation cycles with 1:1 water-ethanol solution, and was resuspended in water for storage in a freezer. Finally, the material was lyophilized under a vacuum of $1.33 \times 10^{-4}$ bar (Supermodulyo Freeze Dryer, Thermo Fisher Scientific Inc., Kansas City, MO, USA), yielding a white powder.

\subsection{Phosphate adsorption by ion exchange}

The phosphate adsorption capacities of the isomorphic structured LDHs ([Mg-Al]-LDH and [Zn-Al]-LDH) were evaluated by ion exchange process using different potassium phosphate solutions. $500 \mathrm{mg}$ of the LDH was added to $250 \mathrm{~mL}$ of $\mathrm{KH}_{2} \mathrm{PO}_{4}$ solution (concentration range from $112.64 \mathrm{mg} \mathrm{L}^{-1}$ to $4505.60 \mathrm{mg} \mathrm{L}^{-1}$ - this range of values includes the phosphate concentrations found at effluents from different human activities) that had been previously equilibrated at $75^{\circ} \mathrm{C}$, with adjustment to $\mathrm{pH} 7.0$ using $0.1 \mathrm{M} \mathrm{NaOH}$, to guarantee the well preservation of $\mathrm{LDH}$ structure. The mixture was continuously agitated for 24 $\mathrm{h}$ and was then centrifuged at $11,200 \mathrm{~g}$ for $10 \mathrm{~min}$. After the adsorption process, the LDH was lyophilized prior to solid-state characterization analyses.

The concentration of phosphorus was determined according to the molybdate blue procedure: $5 \mathrm{~mL}$ of supernatant was mixed with $2 \mathrm{~mL}$ of ascorbic acid solution $(0.4 \mathrm{M}), 0.2 \mathrm{~mL}$ of citric acid solution $(0.03 \mathrm{M}), 2 \mathrm{~mL}$ of sulfuric acid solution $(4.7 \mathrm{M}), 5.5 \mathrm{~mL}$ of ammonium molybdate $(0.08 \mathrm{M})$, and $0.6 \mathrm{~mL}$ of antimony and potassium tartrate $(0.05 \mathrm{M})$. This mixture was then allowed to react for $15 \mathrm{~min}$ in a water bath at $50{ }^{\circ} \mathrm{C}$, forming a phosphoantimonylmolybdenum blue complex. The concentration of the product was determined using a Lambda 25 UV-Vis spectrophotometer (Perkin Elmer) operated at a wavelength of $880 \mathrm{~nm}$.

\subsection{Characterizations}

$\mathrm{X}$-ray powder diffraction measurements were performed with a Shimadzu XRD 6000 diffractometer, using Ni-filtered $\mathrm{CuK}_{\alpha}$ radiation $(\lambda=1.5405 \AA)$. The diffractograms were acquired at $2 \theta$ of $3-80^{\circ}$, with a scan speed of $2^{\circ} \mathrm{min}^{-1}$. The FTIR analyses were performed using a Bruker spectrometer with spectral resolution of $2 \mathrm{~cm}^{-1}$. The specific surface area measurements were performed by applying the BET (Brunauer-Emmett-Teller) method to nitrogen adsorption isotherm data acquired with an ASAP 2020 instrument (Micrometrics). Scanning electron microscopy (SEM) images were obtained with a JEOL JSM-6701F microscope operated at $15 \mathrm{kV}$. The thermal properties of the LDH materials were evaluated using a TGA Q500 thermogravimetric analyzer (TA Instruments, New Castle, DE) operated under the following conditions: atmosphere of nitrogen at a flow rate 
of $60 \mathrm{~mL} / \mathrm{min}$; heating rate of $10^{\circ} \mathrm{C} / \mathrm{min}$; and temperature range of $25-800{ }^{\circ} \mathrm{C}$. The chemical composition for the samples were obtained by energy-dispersive X-ray spectroscopy (EDX), using a Thermo Noran system coupled to a scanning electron microscope (JEM 2010, JEOL).

\section{Results and Discussion}

\section{1 [Mg-Al]-LDH and [Zn-Al]-LDH materials}

The X-ray diffractograms of the as-synthesized [Zn$\mathrm{Al}]-\mathrm{LDH}$ showed sharp and intense peaks at low values of $2 \theta$, together with clear (110) reflections at higher values of $2 \theta$ that were typical of materials such as LDH and could be indexed by JCPDS card 48-1023. This result confirm that the synthesis method proposed was efficient to obtain crystalline [Zn-Al]-LDH material. The commercial [Mg-Al]-LDH sample also displayed the characteristic peaks of hydrotalcite and could be indexed by JCPDS card 14-0191 (Figure 1). For both materials, the indexed diffractions corresponded to a hexagonal lattice with rhombohedral 3R symmetry. ${ }^{10,11}$

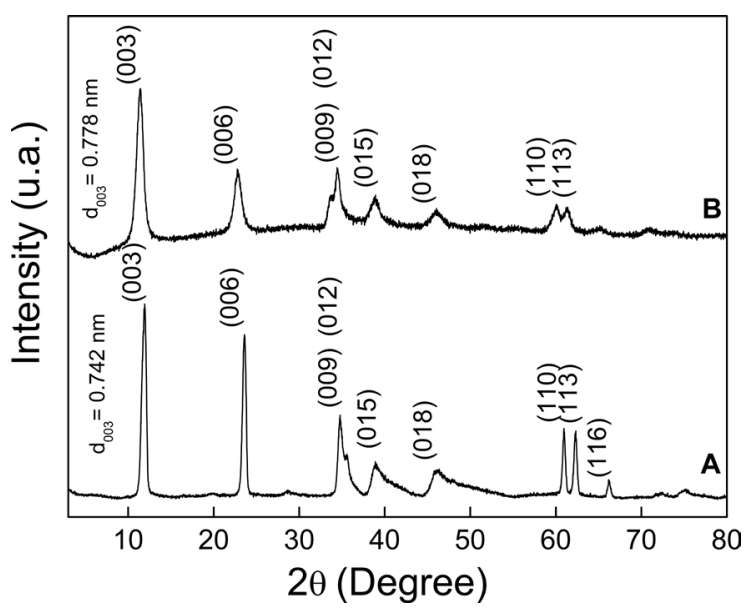

Figure 1. X-ray diffractograms for (A) commercial [Mg-Al]-LDH and (B) the synthesized [Zn-Al]-LDH.

\subsection{Phosphate adsorption by [Mg-Al]-LDH and [Zn-Al]-LDH}

The anion exchange capacity properties of [Mg-Al]-LDH and [Zn-Al]-LDH were evaluated by placing the materials in contact with different phosphate concentrations, under vigorous stirring. The $\mathrm{X}$-ray diffractograms of the $\mathrm{LDH}$ materials after phosphate adsorption are shown in Figure 2. The corresponding amounts of adsorbed phosphate are provided in Table 1. Also, the adsorption isotherms are represented at supplementary information (Fig. S1).

The crystalline structure of [Mg-Al]-LDH was well preserved, even when the material was exposed to higher phosphate concentrations. On (003) diffraction plane no displacements were observed. The highest concentration of adsorbed phosphate was $0.90 \%$ (32.62 $\left.\mathrm{mg} \mathrm{PO}_{4}^{3-} \cdot \mathrm{g}^{-1} \mathrm{LDH}\right)$ when the initial phosphate concentration was $3604.48 \mathrm{mg}$ $\mathrm{L}^{-1}$. Therefore, the adsorbed phosphate probably interacted with hydrotalcite at the external surface. A mechanism of interaction at the external surface involves electrostatic attraction between the negatively charged phosphate species and the surface, which is positively charged due to the presence of protonated hydroxyl groups $\left(-\mathrm{OH}_{2}^{+}\right)^{23}$

Other materials, with low costs production, has been investigate for phosphorous removal from water. The steel slag is an industrial waste derived from a steel factory, however the maximum phosphate adsorption capacity of this material was $5.3 \mathrm{mg} \mathrm{P} / \mathrm{g} .{ }^{24}$ Mesoporous silica materials has the maximum adsorption capacity around $0.40 \mathrm{mmol} / \mathrm{g} .{ }^{25}$ These results demonstrated the high potential of $\mathrm{LDH}$ materials as inorganic matrices for removal of phosphate by adsorption..$^{21}$

The crystalline structure of [Zn-Al]-LDH, was clearly modified as the amount of adsorbed phosphate increased. The typical crystalline structure of the material was well maintained up to the phosphate concentration of $1576.96 \mathrm{mg}$ $\mathrm{L}^{-1}$. While for $2252.80 \mathrm{mg} \mathrm{L}^{-1} \mathrm{PO}_{4}^{3-}$ and higher concentrations the formation of zinc hydroxide ( $\left.\mathrm{Zn}(\mathrm{OH})_{2}\right)$ (JCPDS: 36-1451) was observed, in addition to the typical crystalline structure of [ $\mathrm{Zn}-\mathrm{Al}]-\mathrm{LDH}$. The formation of new phases $\left(\left(\mathrm{Zn}(\mathrm{OH})_{2}\right)\right)$ during phosphate adsorption could be explained by the processes of dissolution and reprecipitation of [Zn-Al]$\mathrm{LDH}$, with the ion exchange process occurring in two steps, involving LDH dissolution followed by reprecipitation of the new phase. ${ }^{26}$ The formation of new phases during the adsorption of phosphate on LDH has also been described in previous studies. ${ }^{27,28}$ The chemical composition for $[\mathrm{Zn}$ $\mathrm{Al}$-LDH samples are represented at supporting information (Fig. S2-S5).

Although crystalline phosphate phases were not observed, there was interaction between the phosphate ions at [ $\mathrm{Zn}-\mathrm{Al}]$ $\mathrm{LDH}$, as revealed by the adsorption of $54.26 \mathrm{mg} \mathrm{PO}_{4}^{3-} \cdot \mathrm{g}^{-1}$ [Zn-Al]-LDH (Table 1, Figure 3B). ${ }^{29}$ As in the case of the commercial hydrotalcite, phosphate could interact with [Zn-Al]-LDH on the external surface, but [Zn-Al]-LDH showed greater efficiency in the adsorption of phosphate by ion exchange in the interlamellar space.

FTIR (Figure 3) was used to identify the interaction of phosphate with [Mg-Al]-LDH and [Zn-Al]-LDH. An intense band at approximately $3450 \mathrm{~cm}^{-1}$ could be attributed to the vibration of water molecules present in the interlayer space, ${ }^{30}$ while bands above $1350 \mathrm{~cm}^{-1}$ were indicative of the presence of $\mathrm{CO}_{2}{ }^{31}$ Vibrations corresponding to metal-oxygen bonds were observed at around 650,550 , and $450 \mathrm{~cm}^{-1} .{ }^{32}$ For [Zn-Al]-LDH the vibrations around $550 \mathrm{~cm}^{-1}$ are correlated to the formation of $\mathrm{Zn}\left(\mathrm{OH}_{2}\right)$ during the phosphate adsorption process. A successful phosphate interaction was verified by the presence of new bands at 1145 and $960 \mathrm{~cm}^{-1}$, related to $\mathrm{PO}_{4}{ }^{3-}$ stretching, confirming the interaction of phosphate with the hydrotalcite layers. Similarly, [Zn-Al]-LDH presented 

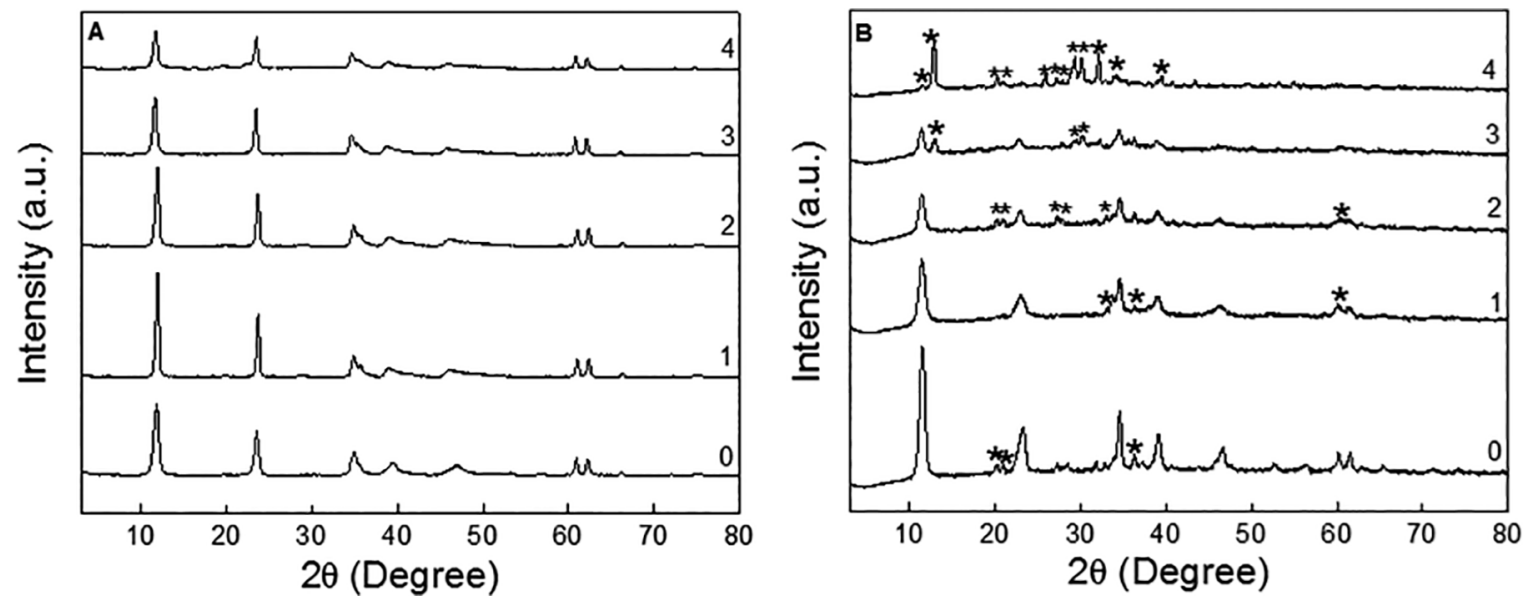

Figure 2. X-ray diffractograms of (A) [Mg-Al]-LDH and (B) [Zn-Al]-LDH. (0) Pure water; (1) $112.64 \mathrm{mg} \mathrm{L}^{-1} \mathrm{PO}_{4}^{3-;}$ (2) $901.12 \mathrm{mg} \mathrm{L}$ $\mathrm{PO}_{4}^{3-;}$; (3) $2252.80 \mathrm{mg} \mathrm{L}^{-1} \mathrm{PO}_{4}^{3-;}$; (4) $4505.60 \mathrm{mg} \mathrm{L}^{-1} \mathrm{PO}_{4}^{3-.}$. *: Zinc hydroxide $\left(\mathrm{Zn}\left(\mathrm{OH}_{2}\right)\right)$.

Table 1. Amounts of phosphate adsorbed by the [Mg-Al]-LDH and [Zn-Al]-LDH materials.

\begin{tabular}{ccc}
\hline $\begin{array}{c}\text { Initial } \mathrm{PO}_{4}{ }^{3} \\
\text { concentration } \\
\left(\mathrm{mg} \mathrm{L}^{-1}\right)\end{array}$ & $\begin{array}{c}{[\mathrm{Mg}-\mathrm{Al}]-\mathrm{LDH}} \\
\left(\mathrm{mg} \mathrm{PO}_{4}{ }^{3-} \cdot \mathrm{g}^{-1} \mathrm{LDH}\right)\end{array}$ & $\begin{array}{c}{[\mathrm{Zn}-\mathrm{Al}]-\mathrm{LDH}} \\
\left(\mathrm{mg} \mathrm{PO}_{4}{ }^{3-} \cdot \mathrm{g}^{-1} \mathrm{LDH}\right)\end{array}$ \\
\hline 112.64 & 0.47 & 14.36 \\
225.26 & 1.39 & 24.45 \\
450.56 & 1.38 & 39.14 \\
901.12 & 3.91 & 43.76 \\
1576.96 & 12.21 & 54.26 \\
2252.80 & 17.93 & 72.69 \\
3604.48 & 32.62 & 73.87 \\
4505.60 & 33.18 & 116.07 \\
\hline
\end{tabular}

new bands at around 1135 and $960 \mathrm{~cm}^{-1}$, suggesting strong interaction of this anion with the [Zn-Al]-LDH matrix, in accordance with the phosphate adsorption capacity of [Zn-Al]-LDH as seen at Table $1 .{ }^{33,34}$

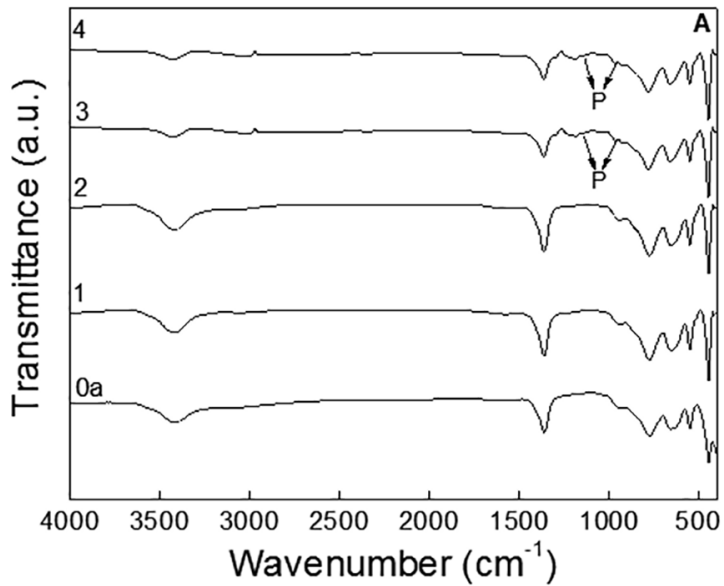

Figure 4 shows SEM images of [Mg-Al]-LDH and [Zn-Al]-LDH, before and after the phosphate adsorption process. The [Mg-Al]-LDH material exhibited the typical hydrotalcite structure, composed of quasi-hexagonal layers (Figure 4A). The typical hexagonal structure was maintained even after the phosphate adsorption (Figures 4B and 4C) in agreement with the XRD results. In contrast, substantial modifications of the [Zn-Al]-LDH structure were observed after phosphate adsorption. Figure 4D shows the pristine [Zn-Al]-LDH, with an irregular nanostructure and layers without the presence of hexagonal structures. The XRD data (Figure $2 \mathrm{~B}$ ) showed that when intermediate phosphate concentrations were adsorbed by [Zn-Al]-LDH, two different crystalline phases were produced, one related to [Zn-Al]-LDH and the other to zinc hydroxide. The corresponding SEM image (Figure 4E) also suggests the presence of these two phases, with predominance of irregular plaques, together with evidence of the deposition of a secondary phase, which was probably zinc hydroxide. When [Zn-Al]-LDH was exposed

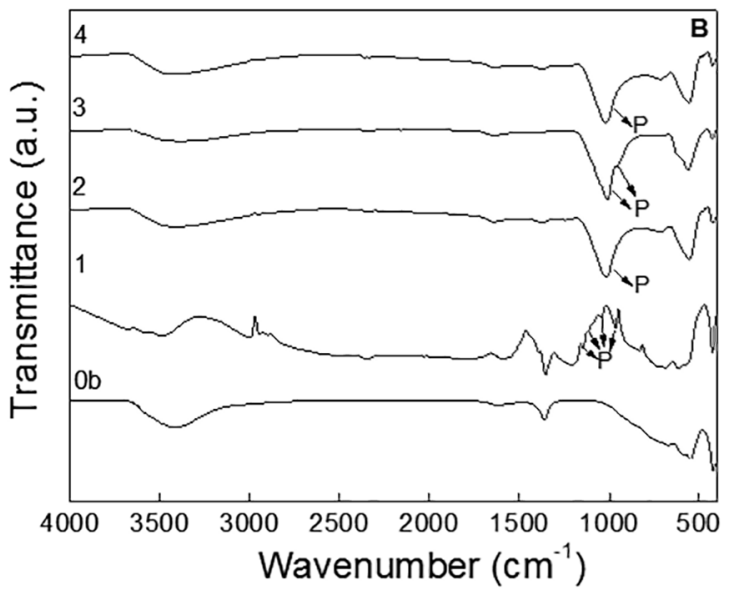

Figure 3. FTIR spectra for (A) [Mg-Al]-LDH and (B) [Zn-Al]-LDH. (0a) Commercial [Mg-Al]-LDH; (0b) pristine [Zn-Al]-LDH; (1) $112.64 \mathrm{mg} \mathrm{L}^{-1} \mathrm{PO}_{4}^{3-;}$; (2) $901.12 \mathrm{mg} \mathrm{L}^{-1} \mathrm{PO}_{4}^{3-;}$; (3) $2252.80 \mathrm{mg} \mathrm{L}^{-1} \mathrm{PO}_{4}^{3-;}$; (4) $4505.60 \mathrm{mg} \mathrm{L}^{-1} \mathrm{PO}_{4}^{3-}$. 

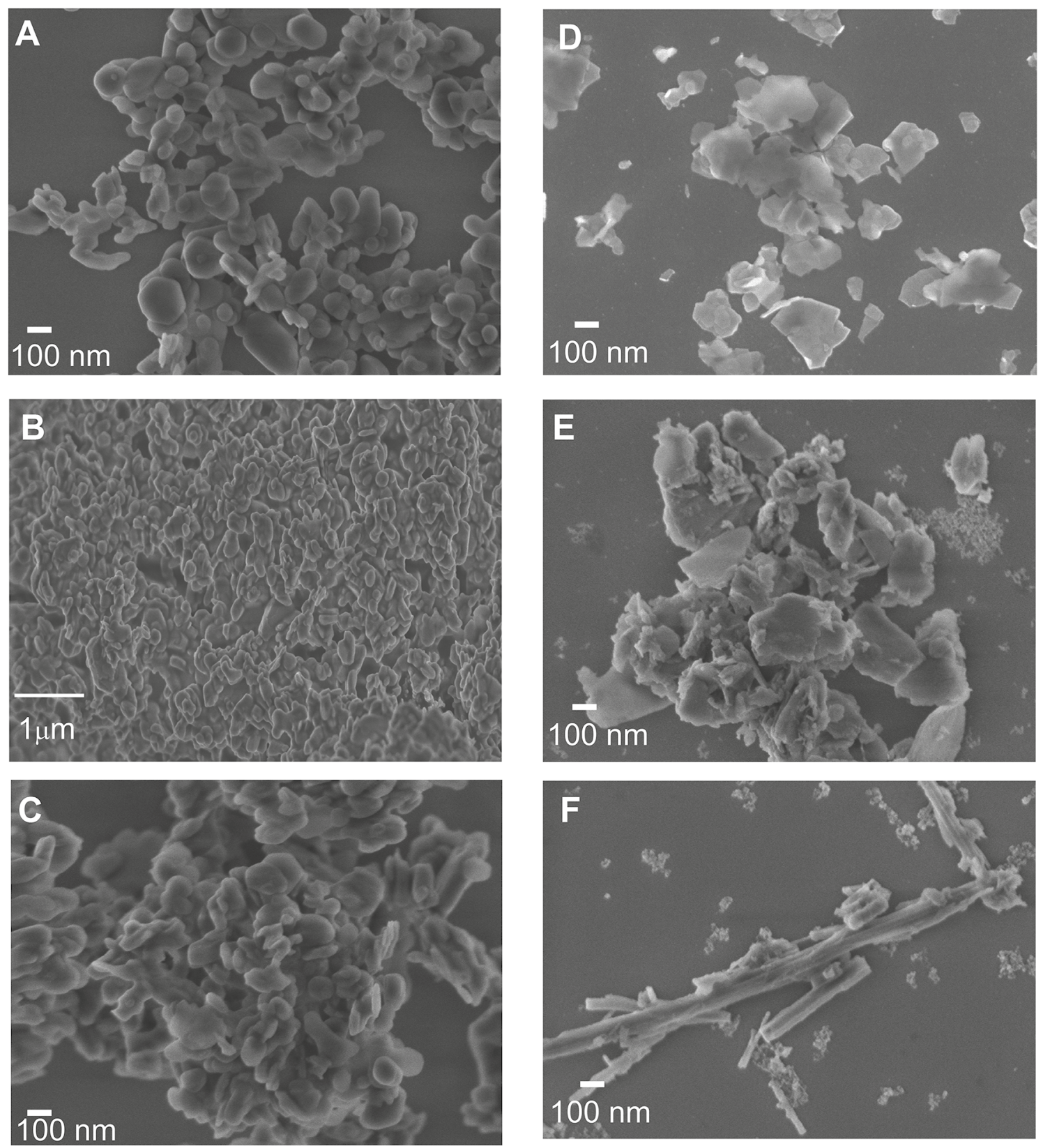

Figure 4. SEM micrographs: (A) Commercial [Mg-Al]-LDH; [Mg-Al]-LDH after adsorption of $2252.80 \mathrm{mg} \mathrm{L}^{-1} \mathrm{PO}_{4}{ }^{3-}(\mathrm{B})$ and 4505.60 $\mathrm{mg} \mathrm{L}^{-1}(\mathrm{C})$; as-synthesized [Zn-Al]-LDH (D); [Zn-Al]-LDH after adsorption of $2252.80 \mathrm{mg} \mathrm{L}^{-1} \mathrm{PO}_{4}^{3-}(\mathrm{E})$ and $4505.60 \mathrm{mg} \mathrm{L}^{-1}(\mathrm{~F})$.

to a high phosphate concentration (Figure 4F), the irregular plaques were replaced by elongated rods, with possible deposition of a secondary phase that was small and highly agglomerated, consistent with zinc hydroxide. ${ }^{35}$

The thermogravimetric and differential thermogravimetric analysis of [Mg-Al]-LDH and [Zn-Al]-LDH loaded with phosphate are shown in Figure 5 and provide further information concerning the compositions of the materials.

TG/DTG for [Mg-Al]-LDH exhibited the same profiles, with sharp peaks regardless of the phosphate concentration (Figures 5A-5C). A small mass loss at around $39{ }^{\circ} \mathrm{C}$ could be attributed to desorption of water from the surface. ${ }^{36} \mathrm{~A}$ mass loss of $12 \%$ above $200{ }^{\circ} \mathrm{C}$ was related to the removal of water adsorbed in the hydrotalcite layers, while a mass loss of $5 \%$ at $278{ }^{\circ} \mathrm{C}$ was associated with the dihydroxylation of [Mg-Al]-LDH. Finally, a $7 \%$ mass loss at $405^{\circ} \mathrm{C}$ was due to the loss of $\mathrm{CO}_{3}{ }^{2-}$ as $\mathrm{CO}_{2} \cdot{ }^{37}$ The dihydroxylation temperature for hydrotalcite is generally observed at around $300^{\circ} \mathrm{C}$ and indicates the thermal stability of the structure, because once dihydroxylation and the loss of the interlayer anion occurs the hydrotalcite structure collapse which leads to the formation of the metal oxide and spinel formation. As the presence of 

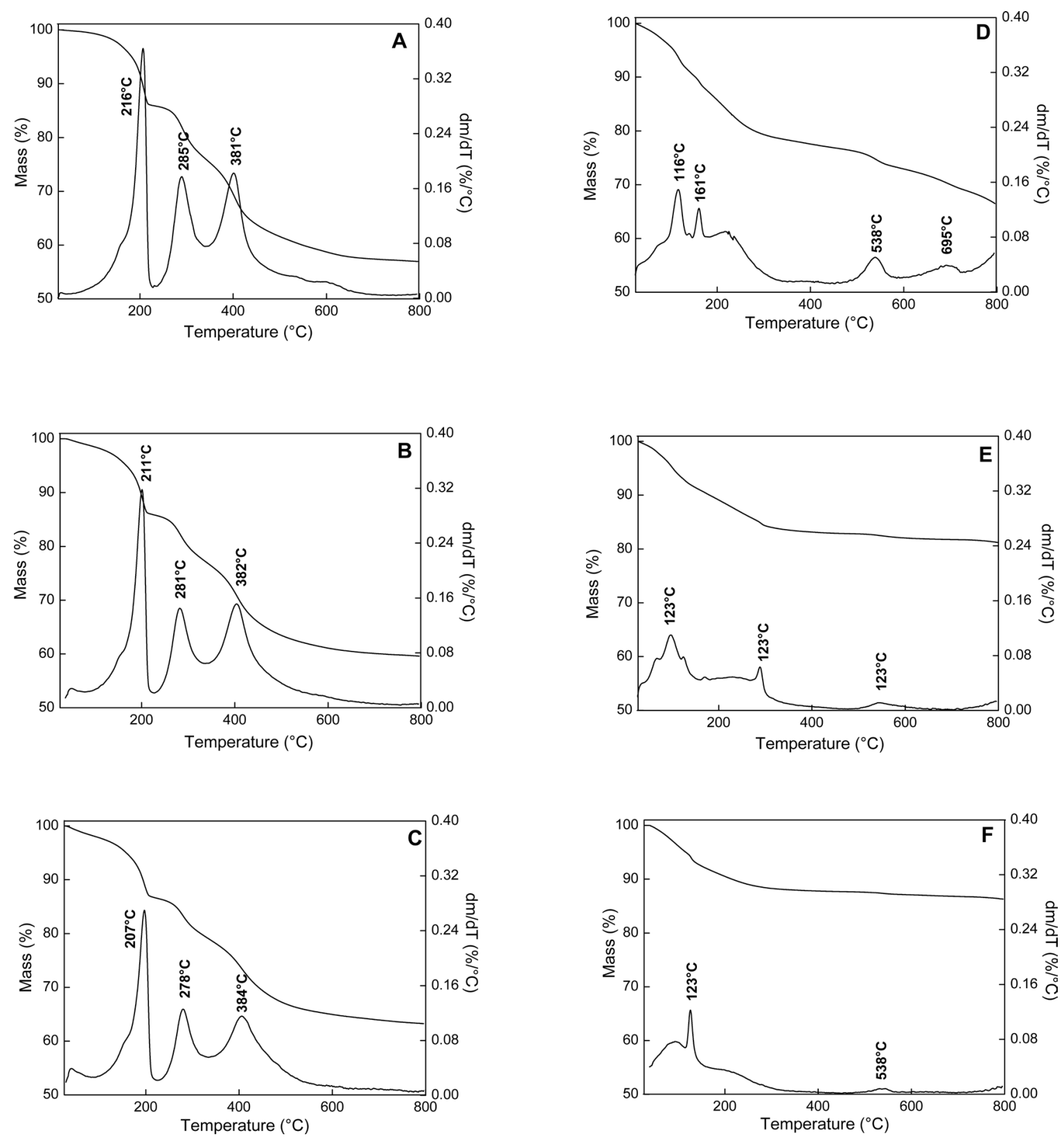

Figure 5. Thermogravimetric (TG) and differential thermogravimetric (DTG) curves of samples loaded with $\mathrm{PO}_{4}^{3-}$ by ion exchange using different initial $\mathrm{PO}_{4}^{3-}$ concentrations: (A) [Mg-Al]-LDH (112.64 $\mathrm{mg} \mathrm{L}^{-1} \mathrm{PO}_{4}^{3-}$ ); (B) [Mg-Al]-LDH $\left(2252.80 \mathrm{mg} \mathrm{L}^{-1} \mathrm{PO}_{4}^{3-}\right)$; (C) [MgAl]-LDH (4505.60 mg L ${ }^{-1} \mathrm{PO}_{4}^{3-}$ ); (D) [Zn-Al]-LDH (112.64 $\left.\mathrm{mg} \mathrm{L}^{-1} \mathrm{PO}_{4}{ }^{3-}\right)$; (E) [Zn-Al]-LDH (2252.80 $\left.\mathrm{mg} \mathrm{L}^{-1} \mathrm{PO}_{4}^{3-}\right)$; (F) [Zn-Al]-LDH (4505.60 $\left.\mathrm{mg} \mathrm{L}^{-1} \mathrm{PO}_{4}{ }^{3-}\right)$.

phosphate on [Mg-Al]-LDH did not interfered on the thermal degradation profile, the TG/DTG technique corroborates the poor interaction of [Mg-Al]-LDH with phosphate. However, in the case of [Zn-Al]-LDH, significant differences were observed between the thermogravimetric profiles obtained at the increasing phosphate concentration adsorbed (Figures 5 $\mathrm{D}, 5 \mathrm{E}$ and $5 \mathrm{~F}$ ). With the increase of phosphate concentration adsorbed, the temperature of loss related to surface water desorption reduces- from around $140^{\circ} \mathrm{C}$ to $120^{\circ} \mathrm{C}$ - as well as the mass loss. When $14.36 \mathrm{mg} . \mathrm{L}^{-1}$ of phosphate was adsorbed at [Zn-Al]-LDH the mass loss related to desorption of the surface water was around $9 \%$, while the adsorption of 72.69 and $116.07 \mathrm{mg} . \mathrm{L}^{-1}$ of phosphate leads to mass loss of surface water of $5 \%$ and $6 \%$, respectively. This event may be related to the phosphate interaction with LDH surface, where phosphate may be interacting with LDH and competing with water molecules for the bond sites. In addition, the bond strength between water and [Zn-Al]-LDH surface is weakened, requiring less energy to be lost, as observed by reduction of the temperature of desorption of surface water. 
Considering the mass loss due to the loss of structural water, only the sample with $72.69 \mathrm{mg} . \mathrm{L}^{-1}$ of phosphate adsorbed had the peak displaced to higher temperatures, therefore this phenomenon may not be related to the phosphate adsorption by $[\mathrm{Zn}-\mathrm{Al}]-\mathrm{LDH}$.

Regardless the amount of phosphate adsorbed on [Zn-Al]$\mathrm{LDH}$, all the samples loss the phosphate around $498^{\circ} \mathrm{C}$ with mass loss around 4\%. ${ }^{38,39}$ That means, that the same fraction of phosphate is weakly interacting with [Zn-Al]-LDH, but considering the samples with higher phosphate concentration adsorbed (Figures $5 \mathrm{E}$ and $5 \mathrm{~F}$ and Table 1), a major fraction of the phosphate are forming thermostable phosphate phase.

Considering one wastewater effluent confined, the obtained phosphate load-LDH could be recovery by traditional techniques (flocculation and/or decantation) and be applied as phosphate fertilizer with controlled or slow release avoiding future widespread contamination by better fertilizer management along time. ${ }^{29,40,41}$

\section{Conclusions}

This work proposes the use of layered double hydroxides (LDHs) as adsorbent matrices for the removal of phosphate from effluents from human activities with high phosphate content. The [Zn-Al]-LDH adsorbent provided efficient removal of phosphate from aqueous solution by means of ion exchange processes. No alteration of the crystalline structure was observed for [Mg-Al]-LDH exposed to different phosphate concentrations. On the other hand, [Zn-Al]-LDH exhibited changes in the crystalline structure following phosphate adsorption, reflecting higher adsorption capacity. At low and intermediate concentrations of $\mathrm{PO}_{4}^{3-}$, the crystalline structure of [Zn-Al]-LDH was well preserved, demonstrating that the ionic interaction mainly occurred on the external surface of the material. At high phosphate concentrations, there was formation of crystalline zinc hydroxide and non-crystalline zinc-phosphate phase. The [Zn-Al]-LDH material exhibited potential for use in phosphate removal from effluent with high phosphate concentration. In order to the effluent reach discharging standards, combination of great methods of phosphate removal could be practiced. The phosphate load-LDH recovered from the confined effluent treatments could be applied as phosphate fertilizer, avoiding future contamination by the better fertilizer management.

\section{Acknowledgements}

The authors are grateful to the Ministry of Science, Technology, and Innovation (through SisNANO Program - National System of Laboratories in Nanotechnology), the National Council for Scientific and Technological Development (CNPq, grant \# 402.287/2013-4), Coordination for the Improvement of Higher Education Personnel (CAPES), Sao
Paulo Research Foundation (FAPESP) and Embrapa Rede AgroNano for their financial support. The authors thank the staff (Paulo Lasso, Adriana Thomazi, and Viviane Farias) and facilities at Embrapa Instrumentação for the support to this work.

Funding details: This work was supported by a $\mathrm{PhD}$ grant from CAPES.

\section{References}

1. Burns RT, Moody LB, Celen I, Buchanan JR. Optimization of phosphorus precipitation from swine manure slurries to enhance recovery. Water Science and Technology. 2003;48(1):139-146.

2. Chimenos JM, FernándezAI, Villalba G, Segarra M, Urruticoechea A, Artaza B, et al. Removal of ammonium and phosphates from wastewater resulting from the process of cochineal extraction using MgO-containing by-product. Water Research 2003;37(7):1601-1607.

3. Faria OLV, Koetz PR, dos Santos MS, Nunes WA. Rice parboilization wastewater phosphorus removal by enhanced biological assimilation in sequencing batch reactor (SBR). Food Science and Technology. 2006;26(2):309-317.

4. Palhares JCP, Calijuri MDC. Characterization of affluents and effluents in swine feeding system and environmental impact qualification. Ciência Rural. 2007;37(2):502-509.

5. Carballa M, Moerman W, De Windt W, Grootaed H, Verstraet W. Strategies to optimize phosphate removal from industrial anaerobic effluents by magnesium ammonium phosphate (MAP) production. Journal of Chemical Technology and Biotechnology. 2009;84(1):63-68.

6. Latifian M, Holst O, Liu J. Nitrogen and Phosphorus Removal from Urine by Sequential Struvite Formation and Recycling Process. Clean - Soil, Air, Water. 2014;42(8):1157-1161.

7. Correll DL. The Role of Phosphorus in the Eutrophication of Receiving Waters: A Review. Journal of Environmental Quality. 1998;27:261-266.

8. Tchamango S, Nanseu-Njiki CP, Ngameni E, Hadjiev D, Darchen A. Treatment of dairy effluents by electrocoagulation using aluminium electrodes. Science of the Total Environment. 2010;408(4):947-952.

9. Yildiz E. Phosphate removal from water by fly ash using crossflow microfiltration. Separation and Purification Technology. 2004;35(3):241-252.

10. Zhou J, Yang S, Yu J, Shu Z. Novel hollow microspheres of hierarchical zinc-aluminum layered double hydroxides and their enhanced adsorption capacity for phosphate in water. Journal of Hazardous Materials. 2011;192(3):1114-1121.

11. Cavani F, Trifirò F, Vaccari A. Hydrotalcite-type anionic clays: Preparation, properties and applications. Catalysis Today. 1991;11(2):173-301.

12. Li F, Duan X. Applications of Layered Double Hydroxides. In: Duan X, Evans DG, eds. Layered Double Hydroxides, Structure and Bonding Series. New York: Springer; 2006. p. 193-223. 
13. Evans DG, Slade RCT. Structural Aspects of Layered Double Hydroxides. In: Duan X, Evans DG, eds. Layered Double Hydroxides, Structure and Bonding Series. New York: Springer, 2006. p. 1-87.

14. Goh K, Lim T, Dong Z. Application of layered double hydroxides for removal of oxyanions: A review. Water Research. 2008;42(67):1343-1368.

15. Ookubo A, Ooi K, Hayashi H. Preparation and phosphate ionexchange properties of a hydrotalcite-like compound. Langmuir. $1993 ; 9(5): 1418-1422$.

16. Das DP, Das J, Parida K. Physicochemical characterization and adsorption behavior of calcined $\mathrm{Zn} / \mathrm{Al}$ hydrotalcite-like compound (HTlc) towards removal of fluoride from aqueous solution. Journal of Colloid and Interface Science. 2003;261(2):213-220.

17. Das J, Das D, Dash GP, Parida KM. Studies on $\mathrm{Mg} / \mathrm{Fe}$ hydrotalcite-like-compound (HTlc) I. Removal of inorganic selenite $\left(\mathrm{SeO}_{3}{ }^{2-}\right)$ from aqueous medium. Journal of Colloid and Interface Science. 2002;251(1):26-32.

18. Wang SL, Liu CH, Wang MK, Chuang YH, Chiang PN. Arsenate adsorption by $\mathrm{Mg} / \mathrm{Al}-\mathrm{NO}_{3}$ layered double hydroxides with varying the $\mathrm{Mg} / \mathrm{Al}$ ratio. Applied Clay Science. 2009;43(1):79-85.

19. Yang Y, Gao N, Chu W, Zhang Y, Ma Y. Adsorption of perchlorate from aqueous solution by the calcination product of $\mathrm{Mg} /(\mathrm{Al}-\mathrm{Fe})$ hydrotalcite-like compounds. Journal of Hazardous Materials. 2012;209-210:318-325.

20. Das J, Das D, Dash GP, Das DP, Parida K. Studies on Mg/Fe hydrotalcite-like - compound (HTlc): removal of Chromium (VI) from aqueous solution. International Journal of Environmental Studies. 2004;61:605-616.

21. Cheng X, Huang X, Wang X, Zhao B, Chen A, Sun D. Phosphate adsorption from sewage sludge filtrate using zinc-aluminum layered double hydroxides. Journal of Hazardous Materials. 2009;169(1-3):958-964.

22. Chitrakar R, Tezuka S, Sonoda A, Sakane K, Ooi K, Hirotsu T. Adsorption of phosphate from seawater on calcined MgMnlayered double hydroxides. Journal of Colloid and Interface Science. 2005;290(1):45-51.

23. Yang K, Yan L, Yang Y, Yu S, Shan R, Yu H, et al. Adsorptive removal of phosphate by $\mathrm{Mg}-\mathrm{Al}$ and $\mathrm{Zn}-\mathrm{Al}$ layered double hydroxides: Kinetics, isotherms and mechanisms. Separation and Purification Technology. 2014;124:36-42.

24. Xiong J, He Z, Mahmood Q, Liu D, Yang X, Islam E. Phosphate removal from solution using steel slag through magnetic separation. Journal of Hazardous Materials. 2008;152(1):211215.

25. Huang W, Zhang Y, Li D. Adsorptive removal of phosphate from water using mesoporous materials: A review. Journal of Environmental Management. 2017;193:470-482.

26. Radha AV, Kamath PV, Shivakumara C. Mechanism of the anion exchange reactions of the layered double hydroxides (LDHs) of $\mathrm{Ca}$ and $\mathrm{Mg}$ with Al. Solid State Sciences. 2005;7(10):1180-1187.

27. Bernardo MP, Moreira FKV, Colnago LA, Ribeiro C. Physicochemical assessment of [Mg-Al-PO $]-\mathrm{LDHs}$ obtained by structural reconstruction in high concentration of phosphate.
Colloids and Surfaces A: Physicochemical and Engineering Aspects. 2016;497:53-62.

28 Bernardo MP, Moreira FKV, Ribeiro C. Synthesis and characterization of eco-friendly Ca-Al-LDH loaded with phosphate for agricultural applications. Applied Clay Science. 2017;137:143-150.

29. Badreddine M, Legrouri A, Barroug A, De Royc A, Bessec JP. Ion exchange of different phosphate ions into the zincaluminium-chloride layered double hydroxide. Materials Letters. 1999;38(6):391-395.

30. Jia Y, Wang H, Zhao X, Liu X, Wang Y, Fan Q, et al. Kinetics, isotherms and multiple mechanisms of the removal for phosphate by Cl-hydrocalumite. Applied Clay Science. 2016;129:116-121.

31. Chang Z, Evans DG, Duan X, Vial C, Ghanbaja J, Prevot V, et al. Synthesis of $\left[\mathrm{Zn}-\mathrm{Al}-\mathrm{CO}_{3}\right]$ layered double hydroxides by a coprecipitation method under steady-state conditions. Journal of Solid State Chemistry. 2005;178(9):2766-2777.

32. Labajos FM, Rivers V, Ulibarri MA. Effect of hydrothermal and thermal treatments on the physicochemical properties of $\mathrm{Mg}$-Al hydrotalcite-like materials. Journal of Materials Science. 1992;27(6):1546-1552.

33. Destainville A, Champion E, Bernache-Assollant D, Laborde E. Synthesis, characterization and thermal behavior of apatitic tricalcium phosphate. Materials Chemistry and Physics. 2003;80(1):269-277.

34. Raynaud S, Champion E, Bernache-Assollant D, Thomas P. Calcium phosphate apatites with variable $\mathrm{Ca} / \mathrm{P}$ atomic ratio $\mathrm{I}$. Synthesis, characterisation and thermal stability of powders. Biomaterials. 2002;23(4):1065-1072.

35. Kanari N, Mishra D, Gaballah I, Dupré B; Mineral Processing and Environmental Engineering Team. Thermal decomposition of zinc carbonate hydroxide. Thermochimica Acta. 2004;410(12):93-100

36. Palmer SJ, Frost RL, Nguyen T. Thermal decomposition of hydrotalcite with molybdate and vanadate anions in the interlayer. Journal of Thermal Analysis and Calorimetry. 2008;92(3):879886.

37. Palmer SJ, Spratt HJ, Frost RL. Thermal decomposition of hydrotalcites with variable cationic ratios. Journal of Thermal Analysis and Calorimetry. 2009;95(1):123-129.

38. Grishchenko RO, Emelina AL, Makarov PY. Thermodynamic properties and thermal behavior of Friedel's salt. Thermochimica Acta. 2013;570:74-79.

39. Sipaut CS, Jafarzadeh M, Sundang M, Ahmad N. Size Control in Porosity of Hydroxyapatite Using a Mold of Polyurethane Foam. Journal of Inorganic and Organometallic Polymers. 2016;26(5):1066-1074.

40. Benício LPF, Constantino VRL, Pinto FG, Vergütz L, Tronto J, da Costa LM. Layered Double Hydroxides: New Technology in Phosphate Fertilizers Based on Nanostructured Materials. ACS Sustainable Chemistry \& Engineering. 2017;5(1):399-409.

41. Everaert M, Warrinnier R, Baken S, Gustafsson JP, De Vos D, Smolders E. Phosphate-Exchanged Mg-Al Layered Double Hydroxides: A New Slow Release Phosphate Fertilizer. ACS Sustainable Chemistry \& Engineering. 2016;4(8):4280-4287. 


\section{Supplementary material}

The following online material is available for this article:

Figure S1. Adsorption isotherms for [Mg-Al]-LDH and [Zn-Al]-LDH

Figure S2. EDX for pristine [Zn-Al]-LDH

Figure S3. EDX for[Zn-Al]-LDH after exposure to solution of $112.64 \mathrm{mg} . \mathrm{L}^{-1}$ of $\mathrm{PO}_{4}^{3-}$.

Figure S4. EDX for[Zn-Al]-LDH after exposure to solution of $450.56 \mathrm{mg}$. $\mathrm{L}^{-1}$ of $^{\mathrm{PO}} \mathrm{C}_{4}^{3-}$.

Figure S5. EDX for[Zn-Al]-LDH after exposure to solution of $4505.60 \mathrm{mg} \cdot \mathrm{L}^{-1}$ of $\mathrm{PO}_{4}{ }^{3}$. 